\title{
Device Characteristics of the GaAs/InGaAsN/GaAs P-n-P Double Heterojunction Bipolar Transistor
}

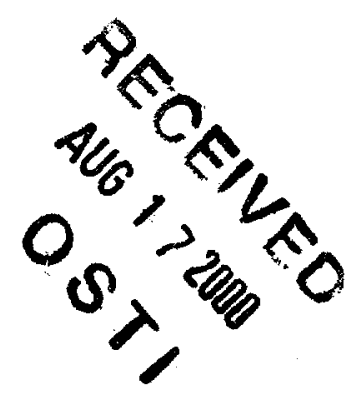

\author{
P. C. Chang, N. Y. Li, A. G. Baca, H. Q. Hou, C. Monier, J. R. Laroche, F. Ren, and S. J. Pearton
}

\begin{abstract}
We have demonstrated a P-n-P GaAs/InGaAsN/GaAs double heterojunction bipolar transistor (DHBT). The device has a low turn-on voltage (VoN) that is $0.27 \mathrm{~V}$ lower than in a comparable P-n-p AlGaAs/GaAs HBT. The device shows near-ideal D. C. characteristics with a current gain $(\beta)$ greater than 45 . The high-speed performance of the device are comparable to a similar P-n-p AlGaAs/GaAs HBT, with $f_{T}$ and $f_{M A X}$ values of $12 \mathrm{GHz}$ and $10 \mathrm{GHz}$, respectively. This device is very suitable for low-power complementary HBT circuit applications, while the aluminum-free emitter structure eliminates issues typically associated with AlGaAs.
\end{abstract}

Index Terms-- InGaAsN, HBT, Aluminum-free, and P-n-p.

\section{INTRODUCTION}

- The trend in portable electronics is to extend the battery lifetime without sacrificing the performance. One approach toward this goal is low-voltage devices that operate at lower power. For heterojunction bipolar transistors (HBTs), a lower bandgap $\left(\mathrm{E}_{\mathrm{G}}\right)$ base reduces the turn-on voltage $\left(\mathrm{V}_{\mathrm{ON}}\right)$, and leads to greater efficiency at low-bias conditions. HBTs with InGaAs bases lattice matched to InP substrates offer one possibility that has not been adopted by commercial foundries due to substrate cost, concern over breakage, and lack of 6" wafers. InGaAsN lattice matched to GaAs is a new material that has received a lot of attention lately. ${ }^{1-5}$ Incorporating small amount of In and $\mathrm{N}$ would result in a significantly reduced

- $\mathrm{E}_{\mathrm{G}}$ compared to GaAs, making it very suitable to lowpower HBT applications. Recently, we demonstrated a N-p-N InGaP/InGaAsN/GaAs double heterojunction bipolar transistor (DHBT) ${ }^{4}$, and a P-n-p AlGaAs/InGaAsN $\mathrm{HBT}^{5}$. Both of these devices show $\mathrm{V}_{\mathrm{ON}}$ that are significantly lower than in their corresponding GaAs based HBTs $^{4-5}$, showing the potential of InGaAsN based HBTs for low power applications.

The complementary heterojunction bipolar transistor (CHBT) technology has the potential for enhanced circuit performance for digital, linear, and microwave applications compared to circuits using only

Sandia National Laboratories, 1515 Eubank S. E., M. S. 0603 , Albuquerque, NM 87123.
N-p-n HBTs. ${ }^{6}$ The focus in this work is the realization of a P-n-P GaAs/InGaAsN/GaAs DHBT, which in conjunction with the N-p-N InGaAsN based HBT technology, would allow the low-power InGaAN based CHBT technology to take advantage of the matured GaAs foundries.

\section{THEORY}

The InGaAsN has received a lot of attention lately mainly due its potentials for optoelectronic applications ${ }^{1-3}$. The $\mathrm{E}_{\mathrm{G}}$ of $\mathrm{GaAs}$ is reduced as In is incorporated, while a compressive strain develops. On the other hand, by adding $N$ into GaAs, a tensile strain develops, while the $E_{G}$ is further reduced. By incorporating proper amount of In and $\mathrm{N}$ into GaAs simultaneously, InGaAsN that is lattice matched to $\mathrm{GaAs}$ can be obtained. The $\mathrm{E}_{\mathrm{g}}$ of the resulting InGaAsN would be significantly lower because of the aggregate $E_{G}$ reduction effect from the incorporation of $N$ and In. The band alignment of the InGaAsN material system is illustrated in Figure $1^{1}$. The InGaAsN that is lattice matched to GaAs would have almost all of its $E_{G}$

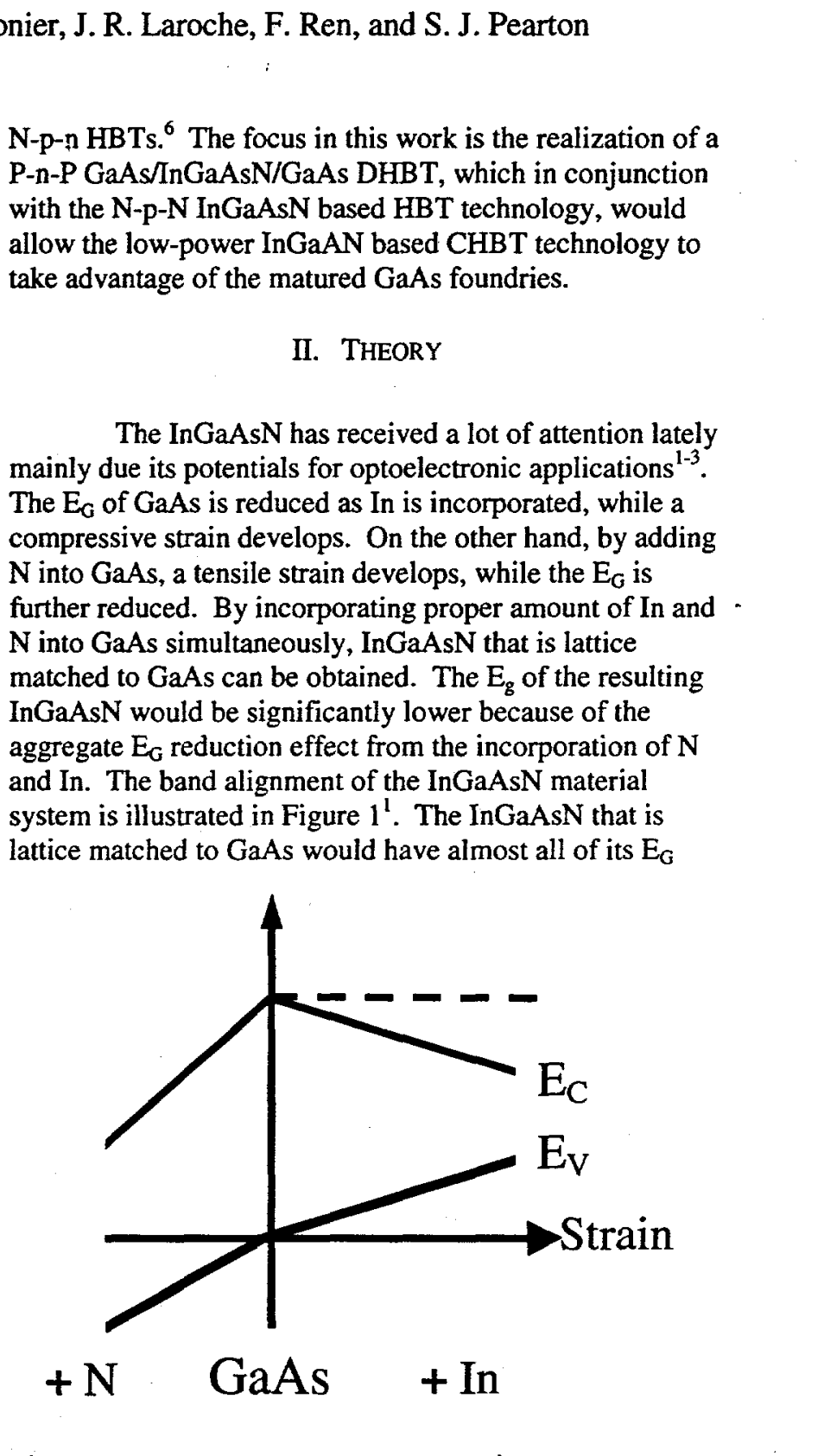

$+\mathrm{N}$ GaAs + In 


\section{DISCLAIMER}

This report was prepared as an account of work sponsored by an agency of the United States Government. Neither the United States Government nor any agency thereof, nor any of their employees, make any warranty, express or implied, or assumes any legal liability or responsibility for the accuracy, completeness, or usefulness of any information, apparatus, product, or process disclosed, or represents that its use would not infringe privately owned rights. Reference herein to any specific commercial product, process, or service by trade name, trademark, manufacturer, or otherwise does not necessarily constitute or imply its endorsement, recommendation, or favoring by the United States Government or any agency thereof. The views and opinions of authors expressed herein do not necessarily state or reflect those of the United States Government or any agency thereof. 


\section{DISCLAIMER}

Portions of this document may be illegible in electronic image products. Images are produced from the best available original document. 
reduction in the form of conduction band $\left(\mathrm{E}_{\mathrm{C}}\right)$ lowering, thus resulting in a large conduction band offset $\left(\Delta E_{C}\right)$ with negligible valence band offset $\left(\Delta \mathrm{E}_{\mathrm{V}}\right)$. This band alignment is especially suitable for P-n-p HBT applications.

In this work, we have investigated application of $\mathrm{In}_{0.03} \mathrm{Ga}_{0.97} \mathrm{As}_{0.99} \mathrm{~N}_{0.01}$ for P-n-P DHBTs. The InGaAsN used in this work is lattice matched to GaAs with an $E_{G}$ of approximately $1.2 \mathrm{eV}$, with almost $0.2 \mathrm{eV}$ of $\Delta \mathrm{E}_{\mathrm{C}}$ when it is stacked next to GaAs. Since the $\Delta \mathrm{E}_{\mathrm{C}}$ is significant while $\Delta \mathrm{E}_{\mathrm{V}}$ is negligible, GaAs can be used as the emitter and the collector material, the hole transport across the emitter-base and the base-collector junction can be achieved without resorting to any exotic junction grading designs. The GaAs collector would allow this device to take advantage of the larger $\mathrm{EG}$ of $\mathrm{GaAs}$, thus allowing good breakdown voltage, in addition, the hole mobility in GaAs is almost 6 time better than in GaAs, thus permitting much improved collector characteristics. Similarly, GaAs is better than AlGaAs as the emitter material because it allows an aluminum-free structure, with improved material properties. Taking advatage of this unique band alignment, we have designe a novel aluminum-free $\mathrm{GaAs} / \mathrm{InGaAsN} / \mathrm{GaAs}$ P-n-P DHBT as shown in Table I, with corresponding band diagram of this structure shown in Figure 2.

Table I : The layer structure of the P-n-P GaAs/InGaAsN/GaAs DHBT.

\begin{tabular}{|c|c|c|c|}
\hline & Material & Thickness $[\AA]$ & Doping $\left[\mathrm{cm}^{-3}\right]$ \\
\hline & $p^{+} \mathrm{GaAs}$ & 3000 & $2.00 \mathrm{E}+19$ \\
\hline Emitter Layer & $p \mathrm{GaAs}$ & 700 & $2.00 \mathrm{E}+18$ \\
\hline Base Layer & $n$ InGaAsN & 1000 & $3.00 \mathrm{E}+18$ \\
\hline Collector Layer & $p^{-} \mathrm{GaAs}$ & 5000 & $3.00 \mathrm{E}+16$ \\
\hline & $p^{+} \mathrm{GaAs}$ & 7500 & $2.00 \mathrm{E}+19$ \\
\hline Substrate & \multicolumn{3}{|c}{ S. I. GaAs } \\
\hline
\end{tabular}

$\mathrm{E}_{\mathrm{C}}$

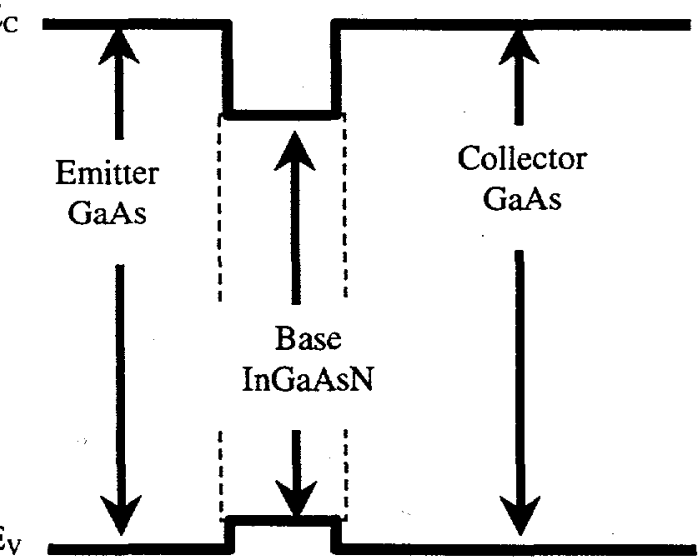

Figure 2: The band diagram of the P-n-P GaAs/InGaAsN/GaAs DHBT.

\section{EXPERIMENT}

The P-n-P DHBT shown in Table I was grown by an Emcore D180 turbodisk reactor. Trimethylindium, trimethylgallium, $100 \%$ arsine $\left(\mathrm{AsH}_{3}\right)$, and 1,1dimethylhydrazine (DMHy) were used as the In, Ga, As, and $\mathrm{N}$ precursors, respectively, for the growth of InGaAsN base layer. The flow rate ratio of DMHy/(DMHy+AsH $\left.\mathrm{D}_{3}\right)$ was fixed at 0.95 . The indium and nitrogen compositions were determined by secondary ion mass spectroscopy and high-resolution $x$-ray diffraction measurements. The doping concentrations in epilayers were confirmed with Polaron and Hall measurements. A comparable P-n-p AlGaAs/GaAs HBT structure was grown along for comparison purpose.

Both devices have been fabricated using a triple mesa process with emitter area of $3 \times 25 \mu \mathrm{m}^{2}$. All three mesa etching processes were performed by wet etching using $\mathrm{H}_{3} \mathrm{PO}_{4}: \mathrm{H}_{2} \mathrm{O}_{2}: \mathrm{H}_{2} \mathrm{O}$ as the etchant. Sputtered WSi served as the emitter metal, while evaporated PdGeAu and TiPtAu were used as the base and collector contact, respectively. A $4000 \AA$ thick layer of $\mathrm{SiO}_{X} \mathrm{~N}_{Y}$ was deposited by ECR for device passivation. The devices are then tested by HP- 4145 for device D. C. characteristics, and HP- 8510 for device R. F. characteristics.

\section{RESULTS}

The GaAs/nGaAsN/GaAs DHBT has a functional current gain $(\beta)$ that is greater than 45 , and the device has nearly ideal IV characteristics as shown in Figures 3 and 4 . Compared to the P-n-p AlGaAs/GaAs HBT, we have observed a significantly reduced $\beta$, which has a $\beta$ of 130 . The $\beta$ reduction is expected because the GaAs/InGaAsN $\mathrm{BE}$ junction does has a reduced $\Delta \mathrm{E}_{\mathrm{C}}$ compared to $\mathrm{AlGaAs} / \mathrm{GaAs}$, in addition, despite recent advance in the InGaAsN material, the crystal quality of the InGaAsN base is still inferior to that of a GaAs base. However, the $V_{O N}$ of the novel InGaAsN DHBT is about $0.27 \mathrm{~V}$ lower than in the comparable GaAs HBT, and even slightly lower than the $0.25 \mathrm{~V}$ for a comparable AlGaAs/InGaAsN HBT reported previously ${ }^{5}$. The resulting offset votlage $\left(\mathrm{V}_{\text {offset }}\right)$ of $0.06 \mathrm{~V}$ is also significantly lower than the $0.13 \mathrm{~V}$ observed in the GaAs HBT. The low-power characteristics are what is expected from the reduced $E_{G}$ in the base material, and from the near-ideal band alignment of the the $\mathrm{BE}$ and $\mathrm{BC}$ junctions.

The $f_{T}$ of the P-n-P GaAs/InGaAsN/GaAs DHBT is about $12 \mathrm{GHz}$, comparable to that of a similar AlGaAs/GaAs P-n-p HBT. The $f_{\text {MAX }}$ of about $12 \mathrm{GHz}$ observed in the InGaAsN device, however, is almost $2 \mathrm{GHz}$ higher than in a similar GaAs based P-n-p HBT. The R. F. characteristics of these devices are compared in Figure 5. These are excellent results considering that they are either comparable to better than in the comparable AlGaAs/GaAs device. The comparable $f_{T}$ values are expected considering 


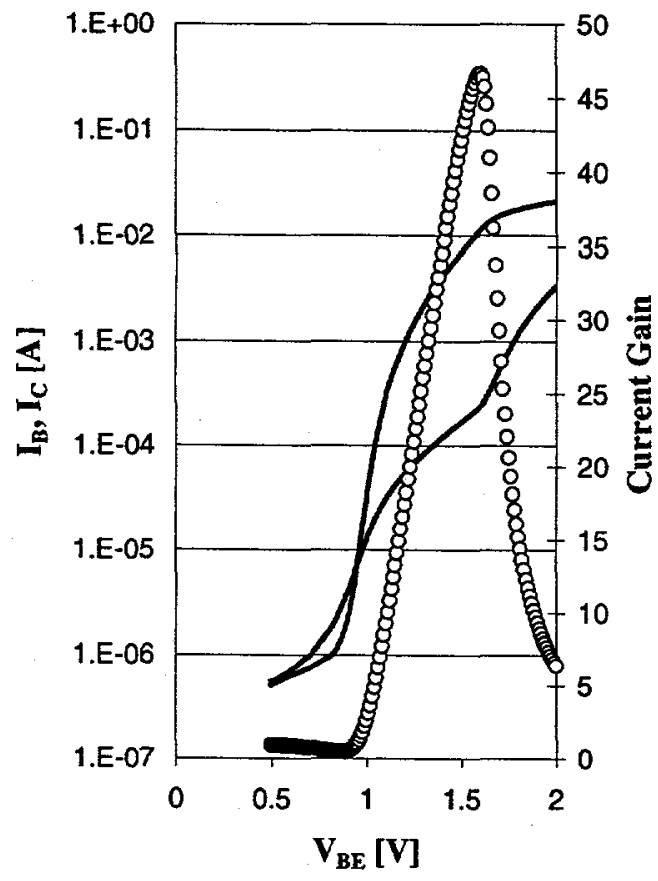

Figure 3 : The Gummel plot of the $3 \times 25 \mu \mathrm{m}^{2} \mathrm{P}-\mathrm{n}-\mathrm{P}$ $\mathrm{GaAs} / \mathrm{InGaAsN} / \mathrm{GaAs} \mathrm{HBT}$. The $\mathrm{B}$ bias is set at 0 V.

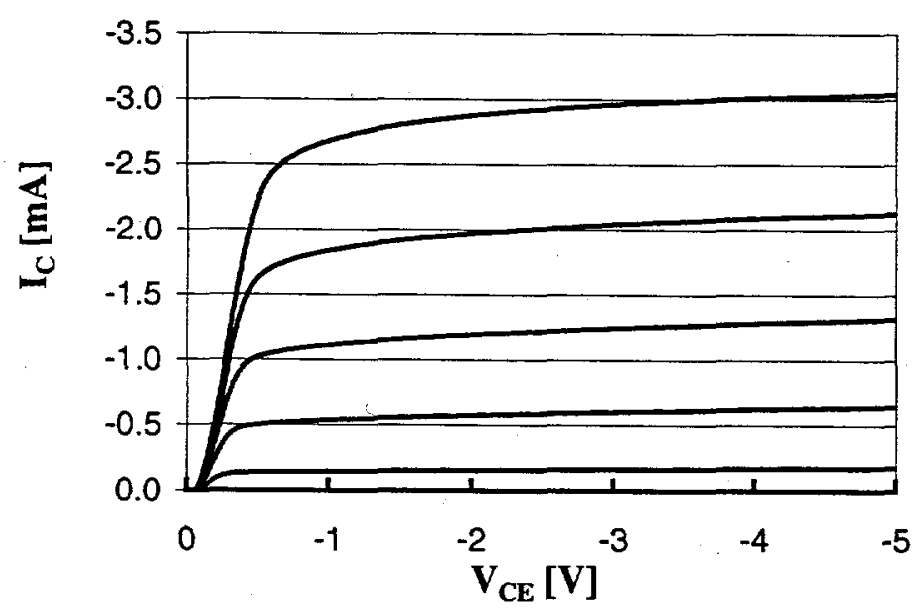

Figure 4 : The common emitter IV characteristics of the $3 \times 25 \mu \mathrm{m}^{2}$ P-n-P GaAs/nnaAsN/GaAs HBT. The base current varies from $20 \mu \mathrm{A}$ to $100 \mu \mathrm{A}$ at 20 $\mu \mathrm{A} /$ step.

that the base layer constitute only a small portion of the total HBT structure, while the GaAs emitter actually provides better hole transport properties than in a AlGaAs emitter, thus the total transit time required for transport a hole thru the HBT structure is not significantly affected. The improved $f_{M A X}$ value, however, is a pleasant surprise probably due to the advantage of GaAs over $\mathrm{AlGaAs}$, and an improved BE junction.

\section{CONCLUSION}

In conclusion, we have demonstrated a GaAs/InGaAsN/GaAs P-n-P DHBT that has shown near-

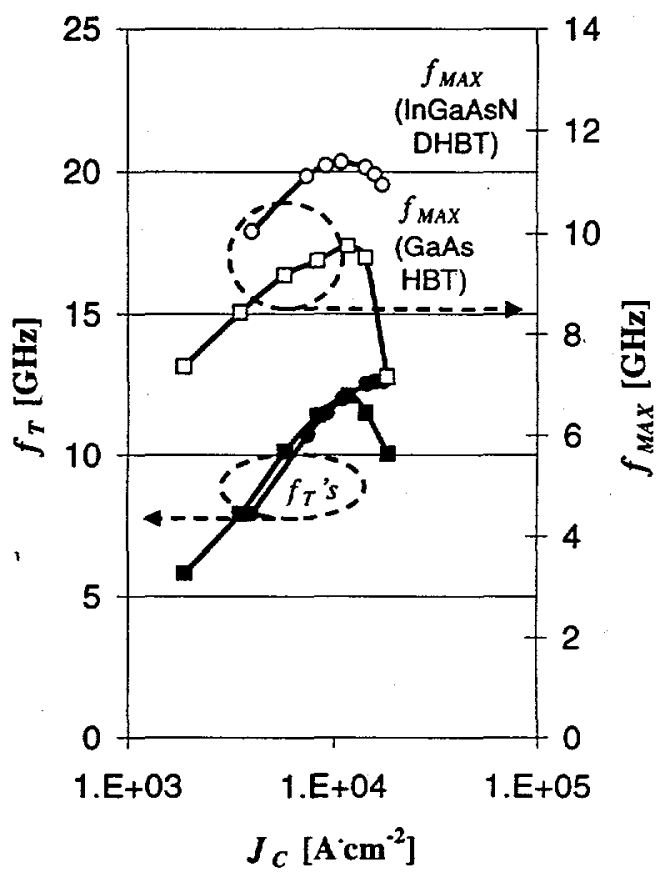

Figure 5 : The $f_{T}$ and $f_{M A X}$ of the GaAs/InGaAsN/GaAs P-n-P HBT, and of the AlGaAs/GaAs P-n-p HBT.

ideal D. C. characteristics with a function $\beta$ of 45 , while its R. F. Characteristics are comparable or better than in a similar AlGaAs/GaAs HBT. The GaAs emitter in this design eliminates the problems associated with $\mathrm{AlGaAs}$ emitters. And the reduced $\mathrm{V}_{\mathrm{ON}}$ of $0.27 \mathrm{~V}$ makes it very useful for low-voltage complementary electronics that can take advantage of the maturing GaAs foundries.

\section{ACKNOWLEDGEMENT}

Sandia is a multiprogram laboratory operated by Sandia Corporation, a Lockheed Martin Company, for the United States Department of Energy under Contract DEAC04-94AL85000.

\section{REFERENCES}

${ }^{1}$ M. Kondow, S. A. Nakatsuka, T. Kitatani, Y. Yazawa, and M. Okai, Jpn. J. Appl. Phys., 1996, 35, pp. 5711-5713.

${ }^{2}$ N. Y. Li, C. P. Hains, K. Yang, J. Lu, J. Cheng, and P. W. Li, Appl. Phys. Lett., 75, 1051 (1999).

${ }^{3}$ H. Q. Hou, K. C. Reinhardt, S. R. Kurtz, J. M. Gee, A. A. Allerman, B. E. Hammons, P. C. Chang, and E. D. Jones, Proc. of the $2^{\text {nd }}$ World Conference and Exhibition on Photovoltaic Solar Energy Conversion, Edited by J. Schmid (The European Comission, Directorate General Joint Research Centre, Environment Institute, Renewal Energy Unit, Ispra,VA, Italy, 1998), p. 3600.

${ }^{4}$ P. C. Chang, A. G. Baca, N. Y. Li, X. M. Xie, H. Q. Hou, E. Armour, Applied Physics Letters, 76, 16, pp. 2262-2264 (2000). ${ }^{5}$ P. C. Chang, A. G. Baca, N. Y. Li, P. R. Sharps, H. Q. Hou, J. R. Laroche, and F. Ren, Applied Physics Letters, 76, 19, pp. 27882790 (2000).

${ }^{6}$ D. Sawdi, and D. Pavlidis, IEEE Tansactions on Microwave Theory and Techniques, 47, 8, pp. 1439 (1999). 